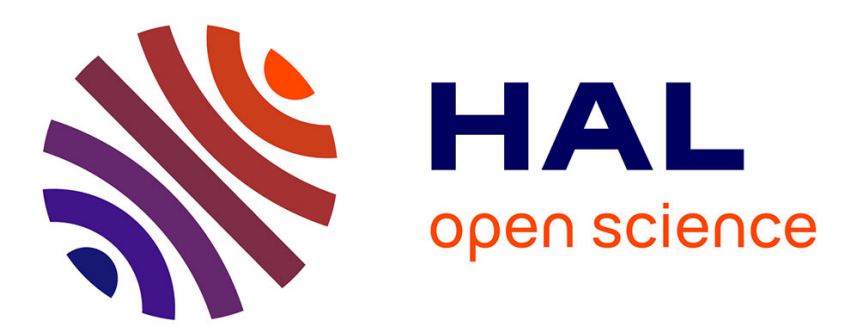

\title{
Measurement and Modeling of the n-channel and p-channel MOSFET's Inversion Layer Mobility at Room and Low Temperature Operation
}

\author{
B. Cheng, J. Woo
}

\section{- To cite this version:}

B. Cheng, J. Woo. Measurement and Modeling of the n-channel and p-channel MOSFET's Inversion Layer Mobility at Room and Low Temperature Operation. Journal de Physique IV Proceedings, 1996, 06 (C3), pp.C3-43-C3-47. 10.1051/jp4:1996306 . jpa-00254224

HAL Id: jpa-00254224

https://hal.science/jpa-00254224

Submitted on 1 Jan 1996

HAL is a multi-disciplinary open access archive for the deposit and dissemination of scientific research documents, whether they are published or not. The documents may come from teaching and research institutions in France or abroad, or from public or private research centers.
L'archive ouverte pluridisciplinaire HAL, est destinée au dépôt et à la diffusion de documents scientifiques de niveau recherche, publiés ou non, émanant des établissements d'enseignement et de recherche français ou étrangers, des laboratoires publics ou privés. 


\title{
Measurement and Modeling of the n-channel and p-channel MOSFET's Inversion Layer Mobility at Room and Low Temperature Operation
}

\author{
B. Cheng and J. Woo
}

Department of Electrical Engineering, University of California, Los Angeles, CA 90095-1594, U.S.A.

\begin{abstract}
A new semi-empirical model for the electron and hole mobilities of the MOSFET inversion layers is proposed. This model takes into account the dependence of Coulombic, phonon, and surface roughness scattering on temperature and transverse field over a wide range of values ( $77 \mathrm{~K} \leq \mathrm{T} \leq 343 \mathrm{~K}$ and transverse fields up to $1.36 \mathrm{MV} / \mathrm{cm}$ ). For the first time, the magnitude of the key parameter $\eta$ in defining the effective transverse field is found to be a continuous function of temperature for both electrons and holes. The $E_{\text {eff }}$ dependences of the universal curves are observed to differ between the electrons and holes, particularly at low temperatures. The proposed model, verified by comparison of experimental data and simulated MOSFET I-V characteristics at different temperatures, can be easily incorporated into 2-D device simulators for device and circuit simulation.
\end{abstract}

\section{INTRODUCTION}

The mobility of carriers in the MOSFET inversion layer has been studied extensively due to its importance in device and VLSI circuit design [1][2]. The previous mobility models are limited to a low transverse electric field and are only useful over a limited temperature range. It is important to have a mobility model valid over a wide temperature range, even down to $77 \mathrm{~K}$, due to recent interest in low temperature CMOS operation.

It has been reported that the electron and hole mobilities in the inversion layer follow universal curves at room temperature, independent of the substrate impurity, oxide thickness, and substrate bias when plotted as a function of effective transverse electric field, $E_{\text {eff }}$, defined by following equation:

$$
E_{e f f}=\frac{1}{\varepsilon_{s i}}\left(Q_{d p l}+\eta Q_{i n v}\right)
$$

where $Q_{d p l}$ is the surface depletion charge density, $Q_{\mathrm{inv}}$ is the surface inversion charge density, and $\varepsilon_{\mathrm{si}}$ is the permittivity of silicon. Here, $\boldsymbol{\eta}$ is an empirical parameter in defining $E_{\text {eff }}$ and was reported to be equal to $1 / 2$ in order to provide the universal relationship. Recent studies show that $\eta$ is not $1 / 2$ for electrons or $1 /$ 3 for holes at all temperatures [3]-[5]. The value of $\eta$ directly affects the precise of mobility modeling. However, the relationship between the $\eta$ and temperature is still not clear. In this work, we propose a new semi-empirical mobility model for the electrons and holes in the MOSFET inversion layer, which is applicable over a wide range of values $(77 \mathrm{~K} \leq T \leq 343 \mathrm{~K}$ and transverse fields up to $1.36 \mathrm{MV} / \mathrm{cm}$ ). For the first time, the magnitude of the key parameter, $\eta$, in defining the electric field is found to be a continuous function of temperature for both electrons and holes. The proposed model is verified by comparison of the experimental I-V curves and those simulated by MEDICI [6] including the new model at different temperatures. 


\section{DEVICE DETAILS AND EXPERIMENTAL TECHNIQUES}

The $n$-channel enhancement-mode MOS transistors were fabricated using $\mathbf{n}+$ poly gate on (100) substrate while p-channel transistors were fabricated using $\mathrm{p}+$ poly gate. To minimize the effects of extrinsic series resistance on the mobility measurements, large area devices $(W / L=100 \mu \mathrm{m} \times 100 \mu \mathrm{m})$ were measured for both NMOS and PMOS. The n-channel devices have $96 \AA$ gate oxide with two surface channel doping concentrations of $3 \times 10^{15} \mathrm{~cm}^{-3}$ and $1 \times 10^{17} \mathrm{~cm}^{-3}$, respectively. The p-channel devices have $130 \AA$ gate oxide and one doping concentration of $5 \times 10^{16} \mathrm{~cm}^{-3}$.

The effective inversion layer mobility, $\mu_{\mathrm{eff}}$, was experimentally extracted from the measured differential drain conductance, $g_{d}$ (with $V_{d s}= \pm 5 \mathrm{mV}$ ):

$$
\mu_{e f f}=\frac{g_{d}}{\frac{W}{L} Q_{i n v}},
$$

where $Q_{\text {inv }}$ is the inversion layer charge per unit area. To avoid the ambiguity in the definition and determination of the threshold voltage, a high frequency split $\mathrm{C}-\mathrm{V}$ method at $10 \mathrm{kHz}$, as shown in Fig. 1, is used to extract $Q_{i n v}$ from the measured gate-channel capacitance, $C_{g c}[7]$. The inversion layer charge is defined as

$$
Q_{i n v}=\int_{-\infty}^{V_{g s}} C_{g c}\left(V_{g s}^{\prime}\right) d V_{g s}^{\prime}
$$

Similarly, the bulk charge density in Eq. $1, \mathrm{Q}_{\mathrm{dpl}}$, is determined by integrating the gate-substrate capacitance, $\mathrm{C}_{\mathrm{gb}}$ :

$$
Q_{d p l}=\int_{V_{F B}}^{V_{g b}} C_{g b}\left(V_{g s}^{\prime}\right) d V_{g s}^{\prime},
$$

where $V_{F B}$ is the flatband voltage. The temperature dependence of the flatband voltage $V_{F B}$ in Fig. 2 was determined by comparing the experimental and simulated C-V curves for the MOS transistors at different temperatures [8].

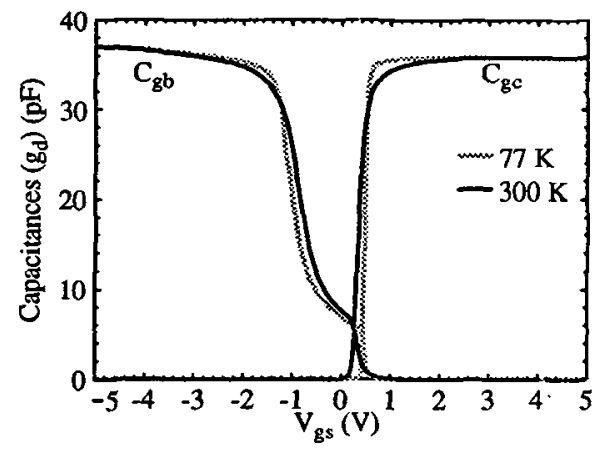

Figure 1. Split C-V measurements of n-channel transistor at $77 \mathrm{~K}$ and $300 \mathrm{~K} . \mathrm{C}_{\mathrm{gb}}$ is the gate-channel capacitance and $\mathrm{C}_{\mathrm{gc}}$ is the gate-substrate capacitance.

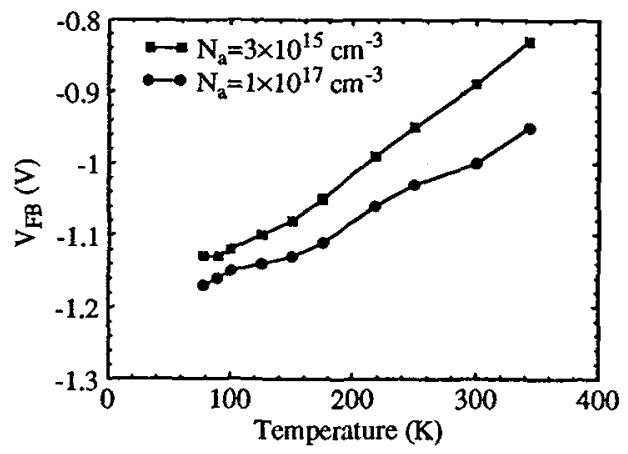

Figure 2. Temperature dependence of the flatband voltage for two different $n$-channel doping devices.

\section{RESULTS AND DISCUSSION}

It has been found that the universal mobility-field curves, as shown in Figs. 3 and 4 , result only if the effective field in Eq. 1 is defined differently for electrons and holes. The parameter $\eta$ in the definition of $E_{\text {eff }}$ was chosen so that the experimental data for $\mu_{\text {eff }}\left(E_{e f f}, N_{a}, V_{\text {sub }}\right)$ fall on a single curve for sufficiently 


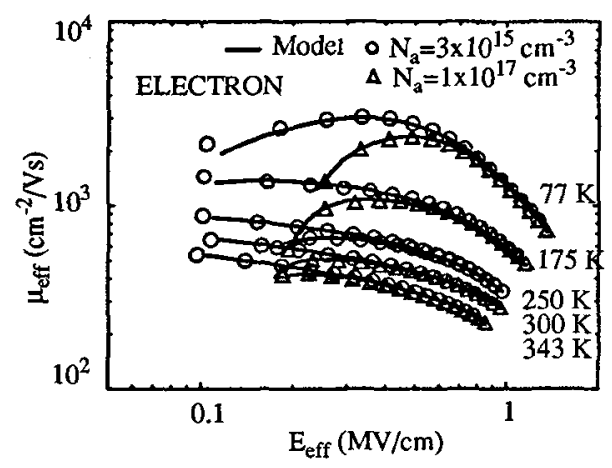

Figure 3. Transverse effective electric field $\left(E_{\text {eff }}\right)$ dependence of the inversion layer mobility for $\mathrm{n}$-channel devices at temperatures $77 \mathrm{~K}, 125 \mathrm{~K}, 250 \mathrm{~K}, 300 \mathrm{~K}$, and $343 \mathrm{~K}$. Symbols correspond to experimental data, while solid line represent the mobility given by Eq. 6 .

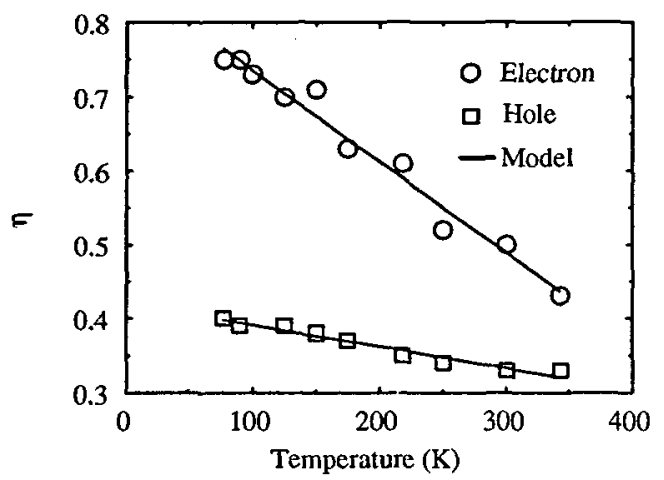

Figure 5. Temperature dependence of the electric field parameter for electrons and holes at temperature range from $77 \mathrm{~K}$ to $343 \mathrm{~K}$.

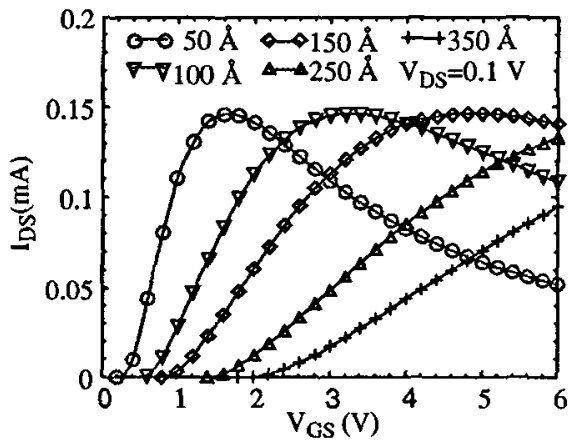

Figure 7. Simulated NMOS linear-region drain currents versus gate voltage with different gate oxide thicknessby including the new mobility model at $77 \mathrm{~K}$.

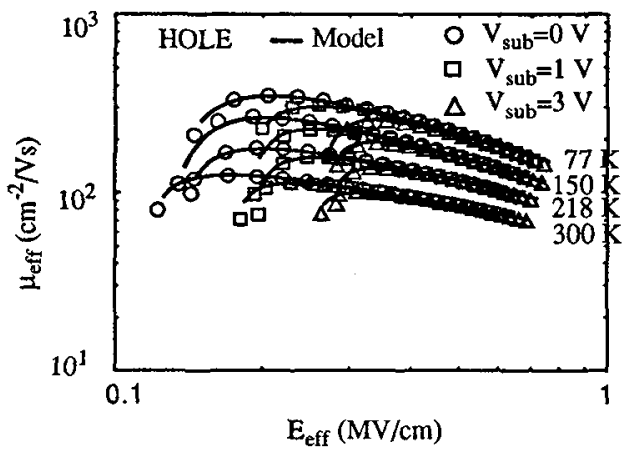

Figure 4. Transverse effective electric field $\left(\mathrm{E}_{\mathrm{eff}}\right)$ dependence of the inversion layer mobility for p-channel devices at temperatures $77 \mathrm{~K}, 150 \mathrm{~K}, 218 \mathrm{~K}$, and $300 \mathrm{~K}$. Symbols correspond to experimental data, while solid line represent the mobility given by Eq. 6 .

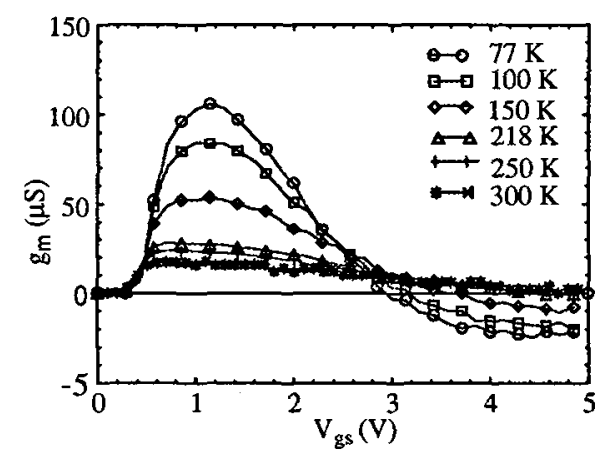

Figure 6. NMOS linear-region transconductances $g_{m}$ versus gate voltage at $77 \mathrm{~K}, 100 \mathrm{~K}, 150 \mathrm{~K}, 218 \mathrm{~K}, 250 \mathrm{~K}$, and 300 $\mathrm{K}$. Negative transconductances are observed at $\mathrm{T}<218 \mathrm{~K}$.

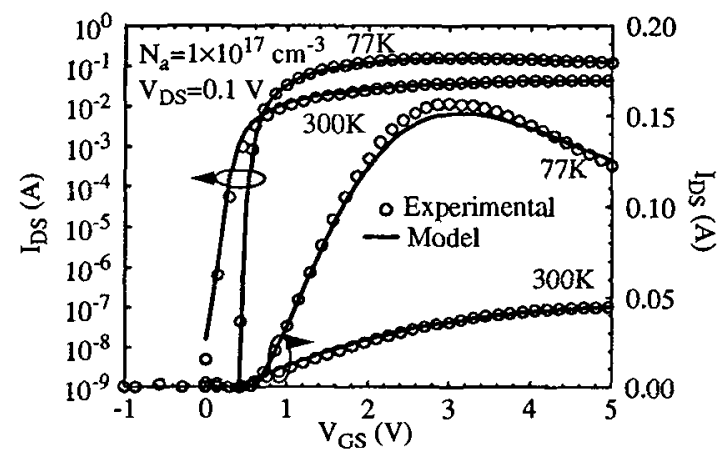

Figure 8. Measured and simulated subthreshold and linear characteristics of a $100 \mu \mathrm{m} \times 100 \mu \mathrm{m}$ NMOS devices at $77 \mathrm{~K}$ and $300 \mathrm{~K}$. 


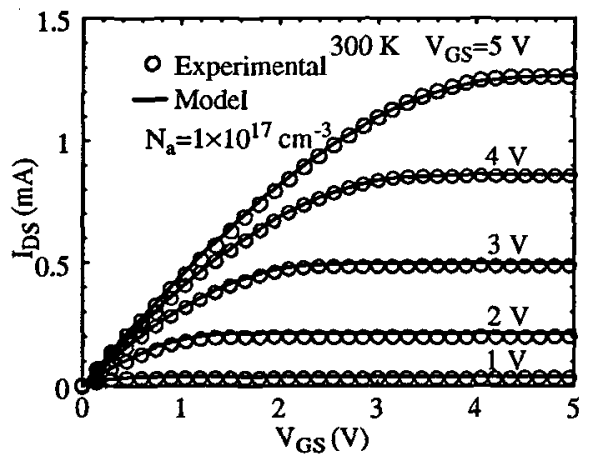

Figure 9. Measured and simulated saturation characteristics of $100 \mu \mathrm{m} \times 100 \mu \mathrm{m}$ NMOS devices at $300 \mathrm{~K}$.

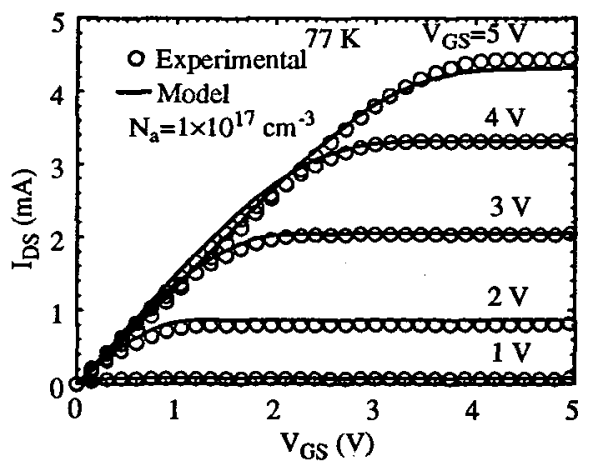

Figure 10. Measured and simulated saturation characteristics of $100 \mu \mathrm{m} \times 100 \mu \mathrm{m}$ NMOS devices at $77 \mathrm{~K}$.

high transverse field at different substrate doping concentrations or substrate bias. The magnitude of extracted $\eta$ is shown in Fig. 5. We found that the $\eta$ values for both electrons and holes are not a constant but have a linear temperature dependence given by $\eta(T)=0.86-1.23 \times 10^{-3} \mathrm{~T}$ for electrons and $\eta(T)=0.42-$ $2.9 \times 10^{-4} \mathrm{~T}$ for holes. The $\eta$ value increases from 0.5 to 0.75 for electrons and from 0.33 to 0.40 for holes as the temperature is reduced from $300 \mathrm{~K}$ to $77 \mathrm{~K}$.

Effective mobility is limited by three scattering mechanisms: phonon scattering $\left(\mu_{\mathrm{ph}}\right)$, surface roughness scattering $\left(\mu_{\mathrm{sr}}\right)$, and Coulombic scattering $\left(\mu_{\mathrm{c}}\right)$. To model these scattering mechanisms, we used a formula similar to that proposed by Watt, et al. [9]:

$$
\begin{gathered}
\frac{1}{\mu_{e f f}}=\frac{1}{\mu_{p h}}+\frac{1}{\mu_{s r}}+\frac{1}{\mu_{c}}, \\
\frac{1}{\mu_{e f f}}=\frac{1}{\mu_{1}}\left(\frac{10^{6}}{E_{e f f}}\right)^{\alpha_{1}}+\frac{1}{\mu_{2}}\left(\frac{10^{6}}{E_{e f f}}\right)^{\alpha_{2}}+\frac{1}{\mu_{3}}\left(\frac{10^{18}}{N_{B}+Q_{f} / z}\right)^{-1}\left(\frac{10^{12}}{Q_{\text {inv }}}\right)^{\alpha_{3}},
\end{gathered}
$$

where $N_{B}$ is substrate doping concentration, $Q_{f}$ is interface state density, and $z$ is the width of the inversion layer given by [10]. The parameters in the proposed mobility model (Eq. 6) can be extracted from the mobility measurements (Figs. 3,4) and are summarized in Table 1. The $\mathrm{E}_{\text {eff }}$ dependence of the universal curves is

Table 1: Parameters of electron and hole mobility model

\begin{tabular}{|c|c|c|c|c|c|c|}
\hline & $\alpha_{1}$ & $\mu_{1}$ & $\alpha_{1}$ & $\mu_{2}$ & $\alpha_{3}$ & $\mu_{3}$ \\
\hline \hline Electrons & -0.22 & $7.25 \times 10^{6} \mathrm{~T}^{-1.71}$ & -2.6 & $2.63 \times 10^{3}-6.59 \mathrm{~T}$ & 1 & $1.63 \times 10^{2}+1.31 \mathrm{~T}$ \\
\hline Holes & -0.32 & $5.80 \times 10^{5} \mathrm{~T}^{-1.5}$ & -1.02 & 125 & 1 & $263.5-0.46 \mathrm{~T}$ \\
\hline
\end{tabular}

observed to differ between electrons and holes, particularly at low temperature. At $77 \mathrm{~K}$, the mobility is dominated by surface roughness scattering. The electron mobility is proportional to $\mathrm{E}_{\text {eff }}{ }^{-2.6}$ while the hole mobility is proportional to $\mathrm{E}_{\text {eff }}{ }^{-1.02}$. This is believed to be due to the different occupancy statistics associated with the lowest subband, where the surface roughness scattering is dominant [11]. At room temperature, the mobility is dominated by the phonon scattering. The phonon limited mobility $\mu_{\mathrm{ph}}$ is proportional 
to $E_{\text {eff }}-0.22$ for electrons and $E_{\text {eff }}{ }^{-0.32}$ for holes, respectively, which is very close to the theoretical calculations [12]. The phonon limited mobility exhibits a temperature dependence of $T^{-1.71}$ for electrons and $T^{-}$ for holes, which can be seen to be very similar for both electrons and holes. Weak temperature dependence is observed for the Coulombic scattering and surface roughness scattering terms, especially for the hole mobility. The values of $\mu_{\text {eff }} v s$. $E_{\text {eff }}$ for electrons and holes obtained from this model are also plotted in Figs. 3, 4, respectively.

In order to concentrate on the effective mobility model, we have limited ourselves to the case of longchannel MOSFET's, where the saturation velocity does not play a significant part in the computation of the I-V characteristics. Good agreement between the experimental I-V curves and those simulated by MEDICI including the new mobility model is obtained for NMOS devices at $77 \mathrm{~K}$ and $300 \mathrm{~K}$, which is shown in Figs. $8,9,10$. Negative transconductance was observed due to strong surface roughness scattering at high $\mathrm{E}_{\mathrm{eff}}$ and $77 \mathrm{~K}$ (Figs. 6, 7).

\section{CONCLUSION}

A new semi-empirical universal mobility model is presented. The definition of effective electric field was revised with a temperature dependent parameter. This model takes into account the dependence of different scattering mechanisms on temperature and transverse electric field over a wide range. The proposed model can be easily incorporated into 2-D simulators for device and circuit simulation over a temperature range from $77 \mathrm{~K}$ to $70^{\circ} \mathrm{C}$.

\section{References}

[1] A. G. Sabnis and J. T. Clemens, "Characterization of electron mobility in the inverted (100) silicon surface," in IEDM Tech. Dig., pp. 18, 1979.

[2] N. D. Arora and G. Gildenblat, "A semi-empirical model of the MOSFET inversion layer mobility for low-temperature operation," IEEE Trans. Electron Devices, vol. ED-34, pp. 89-93, 1987.

[3] A. Hairapetian, D. Gitlin, and C. R. Viswanthan, "Low-temperature mobility measurement on CMOS devices," IEEE Trans. Electron Devices, vol. 36, pp. 1448-1455, 1989.

[4] C. -L. Huang and G. Gildenblat, "Measurement and modeling of the n-channel MOSFET inversion layer mobility and device characteristics in the temperature range 60-300 K," IEEE Trans. Electron Devices, vol. 37, pp. 1289-1300, 1990.

[5] S. Takagi, A. Toriumi, M. Iwase, and H. Tango, "On the universality of inversion layer mobility in Si MOSFET's: part I-effects of substrate impurity concentration," IEEE Trans. Electron Devices, vol. 41, pp. 2357-2362, 1994.

[6] TMA MEDICI: Two-dimensional device simulation program (ver. 1.1.3), Technology Modeling Associates, Inc.

[7] C. G. Sodini, T. W. Ekstedt, J. L. Moll, "Charge accumulation and mobility in thin dielectric MOS transistors," IEEE Sol. State Elec., ED-25, no. 9, pp. 833-841, Sept. 1982.

[8] R. C. Jaeger, F. H. Gaensslen, and S. E. Diehl, "An efficient numerical algorithm for simulation of MOS capacitance," IEEE Trans. Computer-Aided Design of ICAS, vol. CAD-2, pp. 111-116, Apr. 1983.

[9] J. T. Watt, "Modeling the performance of liquid-nitrogen cooled CMOS VLSI," Stanford Elect. Lab. Tech. Rep., No. G725-3, May, 1989.

[10] S. A. Schwarz and S. E. Russek, "Silicon: part II-MOS inversion layer," IEEE Trans. Electron Devices, vol. ED-30, pp. 1634-1639, 1989.

[11] Victor M. Agostinelli, Jr., Hyungsoon Shin, and Al F. Tasch, Jr., "A comprehensive model for inversion layer hole mobility for simulation of submicrometer MOSFET's," IEEE Trans. Electron Devices, vol. 38, pp 151-159, Jan. 1991.

[12] Y. C. Cheng and E. A. Sullivan, "Relative importance of phonon scattering to carrier mobility in Si surface layer at room temperature," Journal of Applied Physics, vol. 44, no. 8, pp. 3619-3625, 1973. 